\title{
Hydrous ferric oxide-magnetite-reduced graphene oxide nanocomposite for detection of arsenic using surface plasmon resonance
}

\begin{abstract}
Surface plasmon resonance sensor coated with hydrous ferric oxide-magnetite-reduced ( $\mathrm{Fe} 2 \mathrm{H} 2 \mathrm{O} 4-\mathrm{Fe} 3 \mathrm{O} 4-\mathrm{rGO})$ graphene oxide nanocomposite film was demonstrated to detect two toxic heavy metals; Arsenic (III) [As(III)] and Arsenic (V) [As(V)] in aqueous solution. The proposed nanocomposite film exhibited successful absorption of As with enhanced sensitivity and selectivity. Resultantly, when tested with different concentrations of $\mathrm{As}(\mathrm{III})$ and $\mathrm{As}(\mathrm{V})$, (0.1-1.0 ppb) the sensor ranged linearly with sensitivity of $2.196{ }^{\circ} \mathrm{ppb}-1$ and $0.960{ }^{\circ} \mathrm{ppb}-1$, respectively, and achieved a detection limit as low as $0.1 \mathrm{ppb}$. These results validate the potential of $\mathrm{Fe} 2 \mathrm{H} 2 \mathrm{O} 4-\mathrm{Fe} 3 \mathrm{O} 4-\mathrm{rGO}$ nanocomposite material for optical sensing applications in as detection.
\end{abstract}

Keyword: Magnetic nanocomposite; Heavy metal ions; Surface plasmon resonance 